\title{
PORQUE ALLÁ NACÍ Y ALLÁ ME CRIÉ. IDENTIDAD Y MEMORIA DE LOS ÚLTIMOS HABITANTES DE LA PAMPA SALITRERA DE TARAPACÁ. 1930-1979. EL CASO DE LOS PAMPINOS DE ARICA*
}

\author{
BECAUSE I WAS BORN AND RAISED THERE. IDENTITY AND MEMORY \\ OF THE PAST RESIDENTS OF NITRATE FIELDS OF TARAPACÁ. \\ 1930-1979. THE ARICA'S PAMPINOS CASE
}

Renato Calderón Gajardo ${ }^{* *}$

\begin{abstract}
Este artículo analiza las representaciones sociales inscritas en distintos testimonios orales de personas que actualmente radican en la ciudad de Arica y que habitaron la pampa salitrera de Tarapacá entre 1930 y 1979, esto con la intención de identificar los significados que envuelven el "ser pampino". La autoidentificación como pampino o pampina es abordada desde las teorías de la identidad y de la memoria, que permiten profundizar tanto en los elementos individuales como colectivos que posee el recuerdo y la transmisión cultural familiar. Se plantea que los pampinos que llegaron a la ciudad de Arica, junto a sus enseres, trasladaron su identidad, la que con el paso de los años fue contribuyendo a la construcción de una memoria colectiva.
\end{abstract}

Palabras claves: Identidad, memoria, salitreras de Tarapacá.

This article analyzes the social representations inscribed in various oral testimonies of people currently living in the city of Arica (northern Chile) and that inhabited the nitrate fields of Tarapacá between 1930 and 1979, this with the intention of identifying the meanings that surround the "be pampino". Self-identification as pampino or pampina is approached from the theories of identity and memory, which can drill in both individual and group elements that has the memory and family cultural transmission. It argues that the pampinos they reached the city of Arica, with their belongings, moved their identity, which over the years was contributing to the construction of a collective memory.

Key words: Identity, Memory, Tarapacá saltpeter.

\section{Introducción}

Abordar este trabajo desde la perspectiva de las representaciones sociales tiene sus fundamentos en la búsqueda de análisis e interpretación de datos con un ímpetu transdisciplinario, en donde el trabajo historiográfico obtiene algunos recursos desde el campo de la psicología social, al que se adscribe el mundo de las representaciones. El análisis e interpretación que se persigue en esta oportunidad es en función de diversos enunciados contenidos en testimonios orales de personas que actualmente residen en la ciudad de Arica, norte de Chile, y que entre los años 1930 y 1979 habitaron en las oficinas salitreras de Tarapacá. Se analizaron 36 testimonios de personas que al momento de la entrevista formaban parte de algún "centro de hijos de la pampa" en Arica. Estos centros congregan a los antiguos pampinos con el objeto de que el pasado vivido en la pampa salitrera no quede en el olvido, ni de sus familias, ni de la ciudad, ni del país. Que los informantes pertenezcan a una agrupación de estas características implica varios aspectos que influyeron en los resultados de la investigación y que son importantes de señalar, como por ejemplo: la socialización de experiencias y de recuerdos. A diferencia de otros sujetos que por diversas razones no se adscriben a este tipo de centros. En este estudio solo se incluyen datos referentes a lo que llamaremos "pampinos asociados". Esto se presenta como una idea fundamental para comprender por qué las representaciones individuales pueden ser vinculadas a una representación colectiva. Se estudiaron todos los enunciados que forman parte de

\footnotetext{
* Resultado Proyecto Fondecyt No 1100074.

** Universidad de Chile, Santiago. Correo electrónico: recalder@unap.cl
} 
una respuesta en particular, cuya pregunta fue: ¿Por qué usted se siente pampino? Ante esta cuestión surgen diversos elementos para el análisis, sobre todo los que se relacionan con la memoria como soporte de la identidad.

Dicho lo anterior, este estudio pretende analizar las representaciones sociales de la identidad y memoria pampina en la ciudad de Arica. Para tales efectos se establecen las siguientes interrogantes; ¿Qué elementos dan impulso a los pampinos de Arica a mantener activa la memoria? ¿Cuáles son los significados contenidos en los discursos de los pampinos? ¿Qué se entiende respecto del concepto de identidad pampina? Y por último se reflexiona en torno a los elementos disímiles que posee el periodo estudiado con las décadas anteriores a 1930. Como una respuesta provisoria se puede señalar que la memoria de los pampinos que residen actualmente en la ciudad de Arica se constituye a partir de la nostalgia por un pasado cargado de experiencias ligadas a la infancia y a la vida familiar. Los significados asociados estarían vinculados a la idealización de una vida mejor que se quedó en la pampa y por ende en el pasado, y que solo es posible acceder a ella mediante la manifestación y socialización del recuerdo. Estos elementos están por sobre las experiencias individuales negativas que principalmente se relacionan al trabajo esforzado y a conflictos familiares. De este modo la infancia y la vida familiar activan una memoria que tácitamente incorpora una tradición familiar y cultural que antecede a sus propias experiencias.

\section{Identidad y Memoria}

Las conceptualizaciones en torno a identidad y memoria pueden entenderse como complementarias en la medida en que ambas se presentan como construcciones sociales, ya sea desde perspectivas individuales como colectivas. John R. Gillis (1996) establece que la vida paralela de estos dos términos nos alerta del hecho que la noción de identidad depende de la idea de memoria y viceversa. La identidad individual o grupal puede permanecer en el tiempo y en el espacio con el respaldo del recuerdo; y lo que es recordado está definido por la identidad asumida. Por el contrario, que las identidades y memorias se transformen con el tiempo tiene su causalidad en el hecho de comprenderlas como si tuvieran un estatus de objetos materiales, memoria como algo a ser recuperado; identidad como algo que puede ser perdido y a su vez encontrado (Gillis 1996). En cuanto a los pampinos de Arica, la identidad individual se fortalece al pertenecer a un grupo, en este caso las agrupaciones de pampinos. Esta sociabilidad permite compartir recuerdos que son asumidos como parte de una sola identidad que se vincula directamente a un pasado pampino. El mismo autor señala que es importante considerar que la identidad y la memoria no son cosas fijas, sino que representaciones o construcciones de realidad, fenómenos más subjetivos que objetivos.

En este sentido, la identidad se caracteriza en cuanto a la percepción que tiene el individuo sobre sí mismo (Mercado y Hernández 2010). Siguiendo este precepto, la percepción sobre sí mismo se complementa con un espacio territorial y con un espacio contextual. Según González (2002), “tiene dos ejes imposibles de separar: el desierto y el salitre. No es posible pensar en la identidad pampina sin hacer referencia al desierto". Este desierto, continúa, fue construido por hombres y mujeres que lo nombraron, lo habitaron y lo hablaron (González 2002:31). Por tanto, el concepto de "pampino" se comprende como una categoría cultural que identifica al habitante del desierto que fue capaz de convertir este espacio árido y desolado en un espacio habitable al que se le denomina pampa, y que desarrolló su cotidianidad ligada, en distintas formas, a la industria del salitre. Una de estas formas es la identidad del obrero pampino que ha quedado en la memoria, tanto del Norte Grande como de Chile, como aquel mecanismo impulsor del movimiento obrero $^{1}$ y protagonista de uno de los sucesos que ha marcado con sangre la historia del país; la masacre de la escuela Santa María de Iquique en 1907, entre otros sucesos de similar índole.

En la actualidad, el pampino del norte de Chile se autoidentifica como tal, debido a su pasado como habitante del desierto, el nexo del ser con el estar y el habitar, desde una perspectiva heideggeriana, se manifiestan de manera simbólica. El carácter indisociable entre identidad y memoria permite comprender, en este caso, que la identidad individual y colectiva se construyen a partir de una memoria también individual y colectiva. Si nos apoyamos en la concepción de Maurice Halbwachs sobre memoria colectiva podemos acercarnos a esta idea de construcción identitaria basada en el pasado, pero no solo el pasado personal, sino que colectivo, cuya memoria también se constituye mediante la socialización de experiencias (Halbwachs 2004). 
Claramente, en el proceso de conformación de identidad mediante la memoria se presentan cuestiones que deben ser consideradas importantes, como por ejemplo la imaginación ${ }^{2}$ y el olvido ${ }^{3}$. La primera, como constituyente fundamental del recuerdo, implica la configuración de imágenes a veces irreales que se separan de toda experiencia real. Mientras que la segunda -el olvido- se presenta de manera constante siendo la misma sociabilidad la que pretende impedir que este envuelva de manera hermética a la memoria.

A partir de lo ya mencionado, lo que se puede entender como una consideración teórica, este trabajo también posee alcances en lo práctico, es decir, en el trabajo de investigación en el área de la memoria y de la identidad colectiva desde una perspectiva histórica.

\section{El Trabajo con la Memoria}

Generar los registros mediante la aplicación de entrevistas es solo una parte del trabajo del investigador que se apoya en la oralidad, porque una vez realizado esto es necesario saber qué hacer con los datos que en algunos casos pueden ser bastantes. El estudio de representaciones nos permite, en primera instancia, indagar en torno al ejercicio de rememoración de los informantes que nos han otorgado su testimonio; en segunda instancia, comprender que la memoria individual forma parte de una construcción social, es decir, de una memoria colectiva; y en tercera instancia, organizar los datos generando categorías de análisis que nos permiten identificar conceptos centrales y periféricos.

En este marco es importante resaltar el proceso del trabajo con registros orales. Al trabajar con este tipo de fuente debemos considerar distintos elementos que influyen al emprender un proyecto, ya sea durante su preparación, su aplicación y su análisis. Primordial es determinar la naturaleza a la que responde la memoria del sujeto, es decir, si las experiencias vividas por él son de orden traumático o de interés cultural para sí mismo y la sociedad. Uno de los aspectos que requiere mayor atención es que los recuerdos evocados por el informante durante la entrevista no necesariamente corresponden a vivencias propias y personales, y además las informaciones entregadas difícilmente se presentarán de manera precisa al señalar fechas o nombres propios. Sin embargo, lo importante es profundizar las temáticas que el sujeto evoca de manera constante, de modo de aprovechar aquellos momentos de destellante lucidez e indagar en los detalles. Sin duda que tal mecanismo obtiene mejores frutos que la preelaboración de una batería de preguntas. Llegado el momento del análisis de datos, el modo tradicional de interpretación de fuentes orales tiene que ver con la saturación de alguna temática tratada en la entrevista, dicha temática alcanza la categorización de "verdad". En aspectos metodológicos, este trabajo pretende demostrar que, mediante el análisis de representaciones sociales, la saturación de datos puede ser explicada en detalle identificando ciertos conceptos claves (centrales y periféricos) a partir de los cuales la interpretación y su explicación extienden su campo.

Antes de profundizar el análisis es pertinente referirse a algunas cuestiones que dan cuenta del contexto en que los pampinos migran a la ciudad de Arica desde finales de la década de 1950, como también del asentamiento y consolidación de estos, que con el paso de los años irán emergiendo distintos focos en donde se hace visible una necesidad de identidad/memoria.

\section{Llegada de los Pampinos a Arica}

Durante el periodo de explotación salitrera bajo la soberanía chilena, tanto el puerto de Iquique como el de Antofagasta se configuraron como unos de los principales puntos de embarque de salitre, no así el puerto de Arica, ya que su ubicación estaba distante de los terrenos calichosos. Sin embargo, Arica fue un destino común para muchos pampinos que debieron migrar a causa de la paralización de las obras productivas en la pampa entre las décadas de 1950 y 1970.

Aquellos recién llegados a Arica-provenientes desde la pampa-debieron sortear las dificultades para conseguir un alojamiento provisorio, pues no poseían bienes inmuebles en la ciudad. Posteriormente, bajo la gestión de la Junta de Adelanto de Arica (JAA), se otorgaron terrenos para la construcción de viviendas definitivas. Algunos de los principales espacios para esto es lo que actualmente se conoce como Población San José, Población Chile, Maipú Oriente, principalmente.

La Comisión de Viviendas de la Junta de Adelanto, para el año de 1959, comenzaba a visualizar el aumento de la población en la ciudad: 
Cuando se aplicó la modalidad de Puerto Libre en Arica (...) junto con el desmantelamiento de las oficinas salitreras, se produjo la llegada de cientos de personas que naturalmente, hicieron gravitar el problema habitacional en forma alarmante en las oficinas de bienes nacionales que no contaban con un equipo técnico que pudiera solucionar el problema $(\ldots)^{4}$.

La población en Arica hacia 1960 aumentó considerablemente con el censo nacional del mismo año en relación con el censo de 1952. Se observa un aumento de 24.397 personas en 8 años, según se puede apreciar en la Tabla 1. Este marcado aumento de población, que alcanza a doblegar las cifras del año 1952, se debe, por una parte, a la creación del Puerto Libre en 1953 y, por otra, la conformación de la JAA en 1958, los que otorgaron a la ciudad de Arica un carácter de seguridad económica convirtiéndola así en un polo de atracción.

El aumento de la población en Arica entre 1952 y 1960 supera en proporción al aumento generado en la ciudad de Iquique, mientras que Arica aumenta en 24.397 personas, Iquique lo hace con un número de 11.079. La tendencia hacia el aumento de población en Arica es evidente, esto continuará durante la década de 1960, por lo que la ciudad se verá en la necesidad de destinar terrenos para la creación de nuevas poblaciones. La Enciclopedia de Arica elaborada por la JAA en 1972 señala lo siguiente respecto de la coyuntura local para 1960:

Una gran ciudad nacía y necesitaba casas, comunicaciones, edificios públicos, urbanización, cultura, y cientos de cosas más que no pasaban por la mente de los apresurados ciudadanos que vendían y compraban con frenesí (Universidad de Chile 1972:43).

Tabla 1. Población de las ciudades de Arica e Iquique según los censos de 1952 y 1960

\begin{tabular}{lcc}
\hline Ciudad & Año 1952 & Año 1960 \\
\hline Arica & 18.974 & 43.344 \\
Iquique & 39.576 & 50.655 \\
\hline
\end{tabular}

Fuente: Instituto Nacional de Estadísticas.
La JAA comenzó a desarrollar una política habitacional para la ciudad, por medio de la Comisión de Viviendas, y señalaba que:

(...) las construcciones se inicien en sectores amplios que constituya grandes núcleos que corresponda a la expansión de una población en constante crecimiento como lo es Arica ${ }^{5}$.

Por lo tanto, ya en 1959 se tenía presente la problemática del déficit habitacional de la ciudad, y para 1960 este déficit alcanzaba 5.578 viviendas ${ }^{6}$. La Comisión de Viviendas señala que las personas que continuaban llegando a la ciudad estaban contribuyendo con el crecimiento de las poblaciones "callampas", en donde las condiciones para la vida no eran las mejores, ya sea por los tipos de viviendas tanto como por la nula urbanización. Esta Comisión identificó un sector en donde se instalaba la población inmigrante generando estas poblaciones callampas, tales sectores comprenden los terrenos ubicados entre las calles Lastarria y 18 de Septiembre ${ }^{7}$. Se comienzan a buscar terrenos para derivar a estas personas, y es entonces cuando aparece la idea de ubicarlos en los terrenos hacia el norte del río San José, en los sectores marginales de la ciudad en ese entonces.

La comisión debatió la moción presentada por los dos miembros de ella [Idro y GuerraConsejeros], que trata de aprovechar los terrenos al norte del río San José, para un plan piloto a fin de ir ubicando organizadamente las construcciones provisorias de la gente que viene llegando de Iquique a causa de la gravísima situación económica por la paralización de las oficinas salitreras (...) La idea de urbanizar las 30 Hás, del sector San José, lotearlas e ir ubicando ordenadamente a esta población y a los que ocupan actualmente terrenos sin autorización en forma que sin interferir construcciones, pueda ser fácil más adelante ir transformándolos a las nuevas viviendas ${ }^{8}$.

Una vez debatida esta moción, solo faltaba la resolución de la Junta de Adelanto, que en febrero de 1960 resuelve comenzar definitivamente con las obras en la población San José, teniendo en consideración diversas actividades a realizar para la construcción y urbanización de la misma9 . 
Hacia 1980 algunos pampinos en Arica comienzan a reunirse en varias agrupaciones culturales con el objetivo de rememorar, basadas en una identidad común, las diversas manifestaciones artísticas y culturales desarrolladas durante su pasado en la pampa salitrera. Estas agrupaciones se mantienen vigentes en la actualidad creando instancias de sociabilidad como veladas, pasacalles, estudiantinas y programas radiales, expresando la nostalgia mediante la poesía, el canto o el baile. De este modo logran evidenciar las prácticas que en otro tiempo eran propias de la vida cotidiana en la pampa ${ }^{10}$.

Estas manifestaciones que forman parte de la diversidad cultural local son desarrolladas a lo largo del año en la ciudad de Arica, como también durante la Semana del Salitre. Esta última es una actividad que reúne anualmente a pampinos (familiares y amigos) que radican en distintas localidades de Chile, en la exoficina salitrera Santiago Humberstone ${ }^{11}$. En dicha reunión anual los pampinos vuelven a poblar y a habitar una oficina salitrera por unos días, añorando el pasado y sacando a flote el anecdotario infaltable de cada año.

La memoria pampina trasciende generaciones y está presente en la cultura y el imaginario del norte, principalmente en Iquique, Antofagasta y localidades cercanas. Con esto se pretende señalar que es frecuente hallar con mayor facilidad cuestiones relativas a la pampa salitrera (ferias, libros, obras de teatro, poetas, músicos, museos) en Iquique y Antofagasta que en Arica, ya que en dichas ciudades (Iquique y Antofagasta) no es necesario haber vivido en la pampa salitrera para desarrollar actividades culturales $\mathrm{o}$ artísticas. La memoria pampina en Arica tiene un matiz distinto, debido a que fue transportada por aquellos que otrora habitaron la pampa y son ellos mismos quienes la manifiestan dando cuenta de la urgencia de difundir un pasado del que no forma parte el resto de la población. Sin embargo, existe, y engalana la multiculturalidad de Arica.

\section{Representaciones de la Memoria y de la Identidad}

La identidad puede ser entendida como una representación que tienen los individuos o grupos de su posición en el espacio social y de su relación con otros individuos o grupos (Mercado y Hernández 2010). Esto indica que la percepción de sí mismo es puesta en contraste permanentemente con otros agentes con el fin de validar su posición y establecer los límites entre identidades. ¿De qué manera interviene la memoria en la identidad como representación? Las representaciones sociales se comprenden como una forma de conocimiento socialmente elaborado y compartido, y orientada a la práctica, que contribuye a la construcción de una realidad común a un conjunto socia (Giménez 1997). Este punto es fundamental para resolver la interrogante propuesta, debido a que una representación social al ser comprendida como un constructo social que es compartido incluye necesariamente elementos identitarios y estos a su vez incluyen cargas de memoria que dan sentido a la identidad.

Para profundizar en la identidad de los pampinos de Arica fue aplicado un análisis cualitativo de las representaciones sociales mediante la Grounded Theory o Teoría Fundamentada. Esto permite tanto el estudio de sus contenidos (aspecto descriptivo) como de su estructura interna (aspecto explicativo). Sus procedimientos de análisis, efectivamente, permiten reconstruir las representaciones en dos etapas: 1) análisis descriptivo y 2) análisis relacional. El objetivo de esta metodología lo constituye una formulación teórica, o un conjunto de hipótesis conceptuales sobre el objeto de estudio (Araya 2002). Junto a ello es fundamental la interpretación analítica del mundo de los individuos, en este caso los pampinos, y de los procesos implícitos con los cuales son construidos esos mundos.

El procedimiento implica tres operaciones:

- Codificación abierta: tratamiento de los datos en bruto. Asignación de códigos y establecimiento de categorías.

- Codificación selectiva: análisis intenso de las principales categorías establecidas en la codificación abierta.

- Codificación teórica: integración de la categoría y sus propiedades, y reducción de categorías por afinidad de conceptos. Lo resultante en esta operación debiese ser el eje central a incorporar en la investigación y comprobación de hipótesis como representación social.

Las entrevistas fueron realizadas en el marco del proyecto denominado "Registros del patrimonio inmaterial y divulgación de la memoria histórica en soporte multimedia: historia oral de los expampinos en la ciudad de Arica", ejecutado en el 2011. Consistió en la aplicación de una entrevista semiestructurada que incluyó como eje central los distintos momentos de la vida de los informantes. Sobre la base de acercamientos previos, se dio cuenta 
de cuatro momentos claves, que son: a) experiencias en la pampa; b) cierre de oficinas y migración; c) llegada a Arica; d) difusión de una identidad y memoria compartida. Para los efectos de este estudio se analizó una pregunta correspondiente al momento d) que tiene relación con la percepción de sentirse pampino y todo lo que esto arrastra.

Las personas que accedieron a entregar su testimonio nacieron y crecieron en el norte. No todos nacieron en una oficina salitrera, pero sí vivieron en una, a excepción de un vendedor itinerante de frutas que debido a su labor recorrió distintas oficinas ofreciendo sus productos (Ver Tabla 2).

De los datos expuestos en la Tabla 2 se pueden extraer distintas observaciones, principalmente respecto de las labores desarrolladas en la pampa. Por una parte, todos vivieron el periodo de infancia en la pampa y por lo tanto asistieron a la escuela. En los testimonios no hay indicios de trabajo infantil, que, como sabemos, antes de 1930 era común la utilización de niños en algunas labores de extracción de caliche ${ }^{12}$. Durante la adultez, la labor femenina se orienta al cuidado de la casa y la familia, mientras que los varones se dedicaban a desarrollar alguna actividad laboral. Llama la atención que solo tres varones hayan desempeñado funciones relacionadas con la elaboración de salitre; un ayudante de cosedor de sacos, un colaborador en el proceso de lixiviación, y un llenador de bateas que más tarde fue polinero. Se da la coincidencia de que son personas que promedian los 80 años de edad y que desarrollaron estas labores durante su juventud. Otro aspecto importante son las labores que comenzaron a desplegar una vez que arribaron a Arica. La industria entonces se presentó como una importante fuente laboral en la ciudad y un gran atractivo para las personas que dieron cuenta del inminente cierre de oficinas.

A partir de los datos recogidos, hemos analizado la significancia que el entrevistado otorga hacia la autoidentificación como pampino. Para ello se procedió a la codificación de enunciados a partir del total de las entrevistas. Es decir, se esquematizó cada respuesta, siendo cada una de estas de-construida tanto por palabras como por frases.

\section{Codificación abierta ${ }^{13}$}

Se realizaron dos líneas de codificaciones, una según la cantidad de palabras mencionadas (seleccionadas en función de la importancia para la investigación), y la otra según la significación de las frases enunciadas. La primera etapa consistió en la codificación abierta, cuyos resultados arrojaron como tres primeras mayorías a las categorías: pampa $(19,2 \%)$, infancia $(15,9 \%)$ y familia $(15,7 \%)$. Cada codificación se conforma por una serie de palabras distintas, de tal modo que la categoría "pampa" se compone de las palabras: pampino(a), pampa y salitre; "infancia" se compone de niño(a), infancia, juegos, juguetes, crianza; y "familia" se compone de padres, hijos, matrimonio, hermanos.

En esta primera etapa de codificación abierta, junto a la categorización de palabras, se codificaron las frases enunciadas por los entrevistados en dos etapas; en la primera se asignó un concepto a cada frase, en la segunda estos conceptos fueron agrupados según su relación en categorías genéricas. Las principales categorías resultantes fueron: a) "autopercepción" (31,8\%), compuesta principalmente por las codificaciones pampino-ariqueño, orgullo y vivencia; b) "infancia" (12,8\%), compuesta por infancia y educación; c) "memoria" $(12,8 \%)$, compuesta por recuerdo, nostalgia y añoranza; d) "familia" $(9,5 \%)$, compuesta por familia, padre, rutina, sacrificio; y e) "percepción histórica" $(8,1 \%)$, compuesta por solidaridad, enganche, raza pampina, sufrimiento, trabajo.

\section{Codificación selectiva}

En esta etapa se extraen las principales categorías de la codificación abierta, tanto de palabras como de frases. Se asignó de forma arbitraria un concepto o categoría central a partir de las relaciones conceptuales. A) Codificación abierta por frecuencia de palabras: Pampa, Infancia, y Familia. B) Codificación abierta por significación de frases: Autopercepción, Infancia, y Memoria. Es posible situar como categoría central a la "identidad pampina", la que se vincula -como una especie de mapa mental- con las ramificaciones que se desprendieron de la codificación abierta. En efecto, la autopercepción, la pampa, la infancia, la familia y la memoria otorgan el sustento a la identidad, la envuelven y la fortalecen.

\section{Codificación teórica}

Los entrevistados se autoidentifican como pampinos por haber habitado en la pampa salitrera. La "autopercepción" se relaciona particularmente 


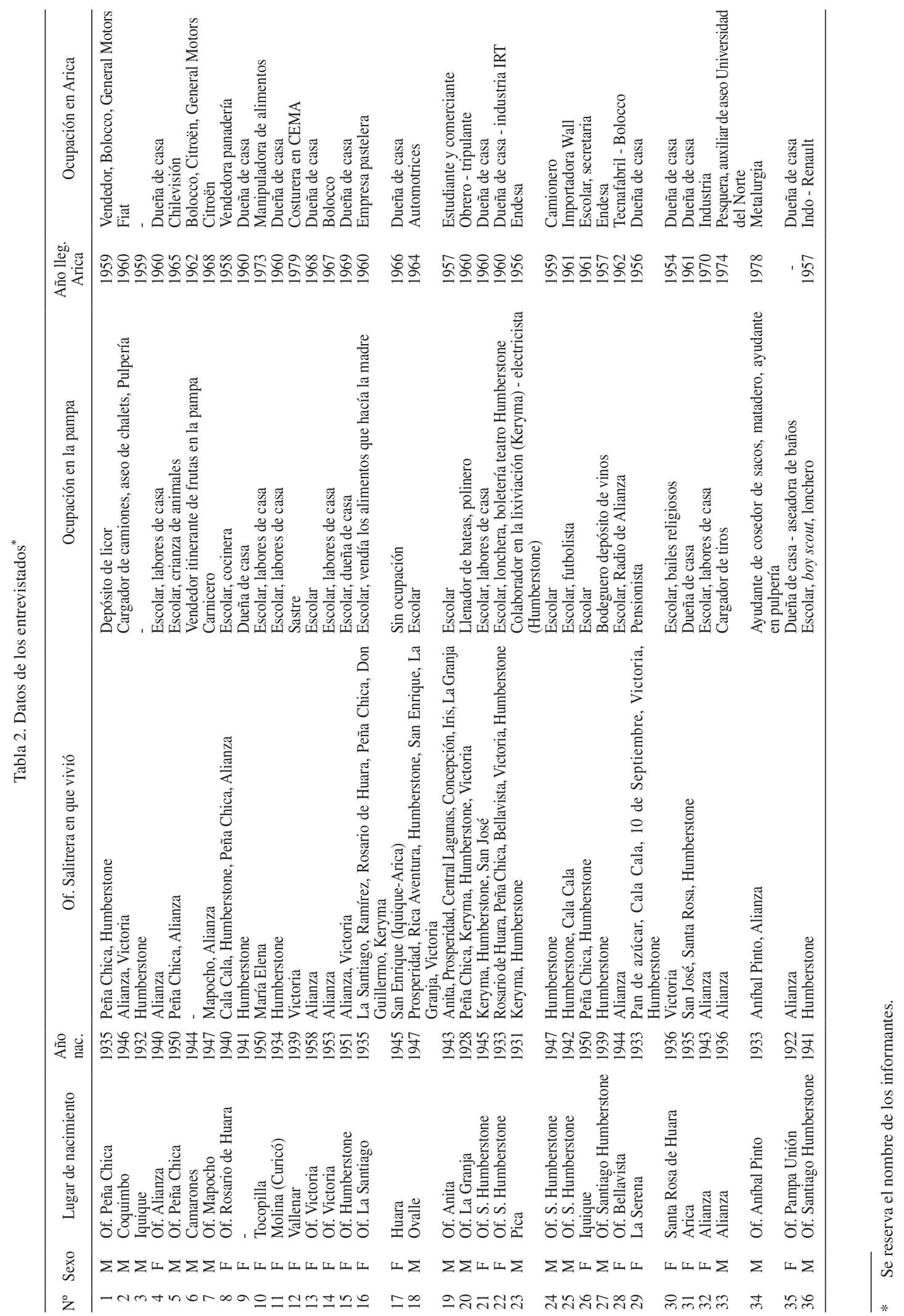


con los códigos "pampino" y "vivencia", lo que tiene directa relación con el vínculo indisociable entre la identificación como pampino y las experiencias vivenciadas en el desierto. Ser pampino significaría estar ligado al desierto, sin importar la distancia geográfica ni la desaparición de oficinas y pueblos salitreros.

\section{"Voy a ser pampina hasta que me muera" (Entrevista 30). \\ "Yo me siento pampina porque yo me hice mujer ahí y yo parí ahî" (Entrevista 32). \\ "Mira me siento bien, [digo] si a todos lados cuando me dicen, yo digo que soy pampina porque le nace a uno, le refleja ser pampino" (Entrevista 17). \\ "Me siento y me creo pampino" (Entrevista 5).}

El abandono y desmantelamiento de los poblados salitreros, que otrora sumaban cientos, no ha sido un impedimento para que el sentido de pertenencia a la pampa, y viceversa, se mantenga activo. Esto se debe en gran parte a las experiencias de vida que tuvieron lugar en la pampa. Estos momentos, ya sean nacimientos, matrimonios o recuerdos de infancia, tienen considerables arraigos en el lugar donde ocurrieron, lo que se puede reflejar en las visitas anuales que los pampinos que hoy radican en distintas ciudades del norte de Chile realizan a las oficinas salitreras donde nacieron o trabajaron.

"De que yo nací allá, me crié, me casé, tuve mi primera guagua, todo eso, yo no reniego" (Entrevista 4).

"Porque aquí nací, porque aquí me crié, aquí me casé, aquí tuve hijos, tengo mi casa" (Entrevista 16).

"Mis raíces, mis raíces que quedaron todas allá, mi niñez, mi juventud, mis padres que se, bueno ellos no eran pampinos, pero se consideraban unos pampinos netos" (Entrevista 28).

"La vivencia, por sobre todas las cosas, la vivencia" (Entrevista 33).

La autoidentificación como pampinos es significativa en la medida en que la "memoria" trae al presente "recuerdos" y "añoranzas" de distintos sucesos ocurridos en las oficinas salitreras. En este punto la memoria cobra relevancia para la identidad, porque le otorga un sustento mediante la abstracción de un pasado que es socializado en el presente. El ejercicio de rememoración, tanto individual como colectivo, es un elemento fundamental para el fortalecimiento de la memoria y de la identidad, y en el caso de los pampinos se desarrolla constantemente en los centros de hijos de la pampa, en programas radiales o en los viajes al desierto.

"yo me recuerdo, me recuerdo de los bailes, me recuerdo del teatro, me recuerdo de tantas cosas, donde jugábamos, de los primeros partidos de fútbol que escuché por radio" (Entrevista 34).

"[...] porque son recuerdos vividos, y tampoco hay gente que dice que es muy sufrido, si sufrido es, por el frío, el calor, pero como le digo pero no es para decir pucha en la pampa perdí toda mi vida, como han dicho algunos" (Entrevista 30 ). "Vienen sus amigos de Iquique, pampinos también, y se juntan ahí en la mesa y empiezan a recordar cuando se iban a la pampa, se iban pa'allá, se iban pa'cá" (Entrevista 12).

Entonces el recuerdo es sostenido por la nostalgia, que pretende recuperar momentos de un pasado que ya no es en un lugar que ya no está.

“¿no sé? Será por la nostalgia de mi papá, de mi mamá, por haber estado allá" (Entrevista 13).

"[...] y la echo de menos la pampa, porque si volvieran las oficinas y me dieran la oportunidad de trabajar en la oficinas, yo me iría a las oficinas" (Entrevista 19). "[...] yo pasé los mejores años de mi vida ahí, los mejores años de mi vida" (Entrevista 34).

"[...] si yo volviera a nacer y volviera a vivir esa vida, la viviría feliz" (Entrevista 25).

Los momentos que activan la memoria se relacionan principalmente con abstracciones que evocan a la "familia" y a la "infancia". Estos recuerdos, que están asociados más a la historia privada o individual de una persona que a una memoria colectiva, al ser compartidos entre pares (pampinos) en el presente, las historias de vida pueden reflejarse entre ellas y 
complementar detalles. Esto ocurre con los juegos y con la etapa de escolarización.

“[...] nosotros nunca tuvimos juguetes como los tienen los niños ahora, nosotros hacíamos nuestros propios juguetes con latas, con tarros de cholgas, con tarros de todo, y hacíamos nuestros juguetes, y la pasábamos bien, y andaban paseando nuestros juguetes, no como ahora, que los niños ocupan juguetes mecanizado, electrónico, nosotros no po, hacíamos nuestros juguetes" (Entrevista 4).

"Era bonito, jugábamos, ahí por eso le digo que hoy en día la juventud no tiene infancia bonita o su niñez que uno lo pasó bonito. Jugábamos harto, como éramos hartas hermanas, jugábamos" (Entrevista 14). "Para mi ser pampina es lo mejor que me ha pasado, yo creo que si hubiese vivido en otra parte no, nacimos ahí, con mi papá nos criamos todo allá" (Entrevista 32).

Los recuerdos familiares cobran un sentido "público" al ser socializados. El mundo privado de la familia pampina se abre y entra a la historia de otras familias, al menos hasta donde sea posible. Es común observar en los relatos la añoranza acerca de la vida familiar, donde los roles estaban bien definidos y la disciplina era rígida.

“[...] entonces no hay eso que tú llegabas a la hora de almuerzo se sienta el papá, se sienta la mamá y toda la familia, todos los pollitos al lado, entonces esa es la diferencia de vivir" (Entrevista 25).

“[...] la gente conocía, respetuosos, conocí a mi señora, nos casamos y con hijos ahí mismo, entonces el recuerdo es muy profundo, muy amplio, y yo me recuerdo" (Entrevista 34).

"Si pues, de momento que estuve tantos años allá, además que nacieron todos mis hijos allá, se criaron, ya después, acá recién han tomado estado ya, terminaron, estudiaron" (Entrevista 35).

\section{Comentarios finales}

La "identidad pampina" se presenta como una síntesis que permite identificar las representaciones contenidas en los discursos de los entrevistados, especialmente ante la pregunta que indaga en el significado del "ser pampino". En efecto, esta identidad se asocia a una memoria familiar y de infancia que se resiste al olvido.

Se pueden establecer tres hipótesis a partir de la aplicación de la teoría fundamentada: a) los entrevistados se autoidentifican como pampinos a causa de haber habitado en la pampa salitrera formando parte de una tradición cultural transgeneracional; b) la autoidentificación como pampinos es significativa en la medida en que la "memoria" trae al presente "recuerdos" y "añoranzas" de distintos sucesos ocurridos en las oficinas salitreras; c) estos momentos que activan la memoria se relacionan principalmente con abstracciones que evocan a la "familia" y a la "infancia".

Aquellos que habitaron la pampa, adhieren su pasado de pampinos a una identidad individual y colectiva que marca una diferencia con un "otro" no pampino, el que podría ser el ariqueño o el andino. Para los pampinos, el ejercicio de rememoración otorga espacio a la inclusión y da forma a una identidad común, cuyo sustento radica en la memoria y en el recuerdo de experiencias comunes asociadas a una etapa de crisis de la industria salitrera, pero que sin embargo fue muy distinta a la industria del periodo de esplendor anterior a 1930. La implementación de diversos espacios para la sociabilidad como teatros, mercados, escuelas, plazas, etc., y además la regulación del trabajo y de la seguridad social son significantes para diferenciar periodos y al mismo tiempo suficientes para comprender la "añoranza" de ese pasado en el desierto. Los pampinos han asumido la responsabilidad de mantener, en constante latencia, que la pampa está viva, a pesar de que las oficinas salitreras hoy estén despobladas, incluso son portadores de una herencia familiar y cultural que los vincula con las luchas sociales y el desarrollo del movimiento obrero, lo que refleja que la identidad no solo se compone de la memoria experiencial, sino también de una memoria social.

La relación existente entre identidad y memoria es posible de evidenciar en los resultados del estudio. La memoria se activa cuando están lejos de la pampa ${ }^{14}$, es decir, al migrar a Arica, a mediados del siglo XX, debieron asentarse y buscar estabilidad, una vez logrado aquello comenzaron a surgir algunos focos que pretendían revitalizar una identidad que estaba dispersa. Hacia 1981 surge la primera agrupación de pampinos en Arica, la 
que fue llamada "Pampa y Mar", estableciendo el nexo entre un pasado habitado en el desierto y un presente habitado en una ciudad costera. De ahí en adelante muchas personas, hombres y mujeres, se sumaron a esta agrupación y posteriormente crearon otras. El principal impulso que poseen para llevar adelante el estandarte de la identidad es un pasado digno de ser contado y de pertenecer a una tradición cultural que con ellos expiró, al menos en la pampa. Y la principal preocupación es evitar que la gente, la ciudad y el país "olvide" que el desierto fue habitado y ocupado, un desierto que fue escenario de distintas experiencias individuales y colectivas que aún permanecen en la memoria. Y no fue habitado solo por ellos, sino que por sus padres y abuelos que vivieron etapas duras de la explotación salitrera distintas a las que ellos vivenciaron. Esta emergencia de mantener activa la identidad se relaciona directamente con uno de los principales simbolismos de los pampinos del norte grande y se presenta a modo de grito de batalla: ¡que la pampa nunca muera!

\section{Referencias Citadas}

Araya U., S.

2002 Las Representaciones Sociales. Ejes teóricos para su discusión, Facultad Latinoamericana de Ciencias Sociales, San José de Costa Rica.

Archivo Histórico Vicente Dagnino. Arica (AHVD)

Artaza, P. et al.

2003 "Patria y clase en los albores de la identidad pampina (1860-1890)", en Historia Vol. 36, 275-332.

Augé, M.

1998 Las Formas del Olvido, Editorial Gedisa, Barcelona.

Barret-Ducrocq, F. (coord.)

2006 ¿Por qué recordar? Con prefacio de Elie Wiesel. Gránica, Buenos Aires.

Calderón G., R.

2010 Ser niño en la pampa: aproximación histórica a la vida cotidiana en la ex oficina salitrera Santiago Humberstone. 1934-1960, memoria para optar al título de Historiador, Universidad de Tarapacá, Arica, Chile.

Gillis, J.

1996 "Memory and identity: the history of a relationship", en John Gillis (editor), Commemorations. The Politics of National Identity, Princeton University Press. Traducción: Natalie Abad de Ruhr.
Giménez, G.

1997 Materiales para una teoría de las identidades sociales, Instituto de Investigaciones Sociales de la UNAM. Recurso digital: http://docentes2.uacj.mx/museodigital/cursos_2008/ maru/teoria_identidad_gimenez.pdf(revisado el 17/07/2012)

González M., S. 2002. Hombres y Mujeres de la pampa. LOM Ediciones, Santiago.

Halbwachs

2004 La memoria colectiva, Prensa Universitaria de Zaragoza, Zaragoza.

Méndez Reyes, J.

2008 "Memoria individual y memoria colectiva: Paul Ricoeur", Revista Agora, Año 11, No 22, Venezuela.

Mercado M., A. et al.

2010 "El proceso de construcción de la identidad colectiva", Universidad Autónoma del Estado de México, № 53 , mayo - agosto, pp. 229-251.

Ricoeur, $\mathrm{P}$.

2003 La memoria, la historia, el olvido, Editorial Trotta S.A., Madrid.

Universidad de Chile

1972 Enciclopedia de Arica. Editorial de Enciclopedias Regionales LTDA, Santiago.

\section{Notas}

1 La identidad pampina en el siglo XIX posee un matiz distinto a la identidad durante diversos momentos del siglo XX. La identidad pampina, que es la identidad del obrero, se encuentra en formación y en el contexto de la Guerra del Pacífico. Esta identidad se caracteriza por una coexistencia de elementos relativos a las ideas de patria y clase. Ver Pablo Artaza et al. Patria y clase en los albores de la identidad pampina (1860-1890). En revista Historia Vol. 36, 2003, 275-332.

2 Paul Ricoeur (2003) establece que existe una relación entre memoria e imaginación, en el sentido de que el ejercicio de recordar se realiza por medio de la actualización de imágenes de momentos del pasado, o dicho de otro modo, cuando se recuerda se hace con imágenes mentales. Paul Ricoeur, $L a$ memoria, la historia, el olvido, Madrid: Editorial Trotta S.A., 2003. A partir de esta idea, es que la veracidad de la memoria es cuestionada y caracterizada como poco fiable, debido a que si la memoria contiene imaginación se la estaría conduciendo al riesgo de lo irreal y lo virtual. Paul Ricoeur, "Definición de la memoria desde un punto de vista filosófico", En: Francoise Barret-Ducrocq (coord.) ¿Por qué recordar?, Buenos Aires: Granica, 2006. El hecho de cuestionar la dimensión verista de la memoria tiene su causa en que se espera que ella sea fiable. En cambio con la imaginación sucede lo contrario. Tiene los permisos para soñar, "ser creativa, inventora, libre, no coartada; en tanto que a la memoria le pedimos que represente con fidelidad, verazmente, aquello que no es, pero que alguna vez fue". 3 Marc Auge (1998) plantea que el olvido es la fuerza viva de la memoria, y que el recuerdo es el producto de esta. Marc Augé, Las formas del olvido, Barcelona: Editorial Gedisa, 1998. Es posible interpretarla de modo tal, que la memoria se presenta como un sistema frágil de retención de información del pasado que está siendo constantemente 
soslayada por el olvido, generando que este último se convierta en un agente envolvente de la memoria dejando escapar, mediante grietas, ciertos destellos de recuerdos que son los que contienen parte de la memoria. El mismo autor, siguiendo a Jean-Bertrand Pontalis, propone que "Lo que queda inscrito e imprime marcas (...) no es el recuerdo sino las huellas, signos de la ausencia. Esas huellas están en cierto modo desconectadas de todo relato posible o creíble; se han desligado del recuerdo". Augè, op cit., 30.

4 Archivo Histórico Vicente Dagnino (En adelante AHVD), Fondo Documental Junta de Adelanto de Arica (JAA), Volumen $\mathrm{N}^{\circ} 4$, Acta $\mathrm{N}^{\mathrm{o}} 10$ del 19/08/1959.

5 AHVD, Fondo Documental JAA, Volumen $\mathrm{N}^{\circ} 4$. Acta $\mathrm{N}^{\circ} 8$ del 11/08/1959.

6 AHVD, Fondo Documental JAA, Volumen $\mathrm{N}^{\circ} 4$. Acta $\mathrm{N}^{\circ} 27$ del 30/08/1960.

7 AHVD, Fondo Documental JAA, Volumen $\mathrm{N}^{\circ} 4$. Acta $\mathrm{N}^{\mathrm{o}} 10$ del 19/08/1959.

8 AHVD, Fondo Documental JAA, Volumen $\mathrm{N}^{\circ} 4$. Acta $\mathrm{N}^{\circ} 18$ del 03/02/1960.

9 AHVD, Fondo Documental JAA, Volumen $\mathrm{N}^{\circ} 4$. Acta $\mathrm{N}^{\mathrm{o}} 18$ del 03/02/1960.
10 Las agrupaciones de expampinos que participaron en este estudio son: Nostalgias Pampinas, Pampa y Mar, Hijos de la Pampa, Alianza, y Peña Chica.

11 La ex-Oficina Salitrera Santiago Humberstone fue declarada Patrimonio de la Humanidad por UNESCO desde el 2005.

12 Para conocer con mayor profundidad la infancia en la pampa salitrera entre 1930 y 1960 se recomienda revisar la siguiente memoria de título; Renato Calderón G., Ser niño en la pampa: aproximación histórica a la vida cotidiana en la ex oficina salitrera Santiago Humberstone. 1934-1960, memoria para optar al título de Historiador, Universidad de Tarapacá, Arica, Chile, 2010.

13 Para poner en práctica el procedimiento propuesto por la Teoría Fundamentada se sistematizaron los datos en el software Microsoft Office y su herramienta Excel, generando bases de datos para así poder filtrar la información.

14 Mercado y Hernández señalan al respecto que "Los individuos experimentan la pertenencia al grupo cuando se relacionan con los miembros de grupos diferentes al suyo; por ejemplo, hay mexicanos que dicen que se sienten orgullosos de serlo cuando están en el extranjero, pero no ocurre lo mismo cuando conviven con los de su propio grupo (Mercado y Hernández 2010). 
